\title{
Concentrações de metais pesados em grãos de café produzidos em lavouras sobre solos originados do basalto e do arenito Caiuá
}

\author{
Heavy metals concentration in coffee grains produced in farming under basalt and \\ Caiuá sandstone soils
}

\author{
Carla Adriana Pizarro Schmidt ${ }^{\mathrm{I}}$ Édison Miglioranza ${ }^{\mathrm{II}}$ Getúlio NagashimaII \\ Fábio Grecco
}

\begin{abstract}
Tendo em vista que o Brasil é um grande produtor RESUMO e consumidor de café, fica evidente a importância de sua caracterização em diferentes locais de cultivo. O objetivo do presente estudo foi quantificar os teores de metais pesados em amostras de grãos de café, provenientes de lavouras implantadas em solos oriundos do basalto e do arenito Caiuá do Estado do Paraná. Foram examinadas 30 amostras de grãos de café, sendo 15 cultivados em solos predominantemente arenosos e 15 em solos argilosos. A determinação de Cromo $(\mathrm{Cr})$, Cobalto (Co), Níquel (Ni), Chumbo (Pb), Cádmio (Cd), Cobre ( $\mathrm{Cu}$ ), Zinco ( $\mathrm{Zn})$ e Manganês (Mn) foi feita por espectrometria de emissão atômica com fonte de plasma induzido com Thermo Jarrel-ash ICAP 612 E (ICP-EAS). Os níveis foram variáveis entre as amostras.
\end{abstract}

Palavras-chave: Coffea arabica, fruto, metais tóxicos, textura do solo.

\section{ABSTRACT}

Considering that Brazil is a big producer and coffee consumer its evident the importance of its characterization in the different places of cultivation. The purpose of the present study was quantify the levels of high metals in coffee grains samples 'IAPAR 59' derived from farming introduced in basalt and Caiuá sandstone soils in Paraná, Brazil . Thirty ground samples were examined, being 15 of predominantly arenaceous ground and 15 of argillaceous ground. The determination of Chrome (Cr), Cobalt (Co), Nickel ( $\mathrm{Ni})$, Lead (Pb), Cadmium
(Cd), Copper ( $\mathrm{Cu}$ ), Zinc ( $\mathrm{Zn})$ and Manganese ( $\mathrm{Mn}$ ), was made through atomic emission spectrometry with induced plasma source with Thermo 612 Jarrel-ash ICAP E (ICP-EAS). The levels changed among the samples.

Key words: Coffea arabica, fruit, toxic metals, texture of the soil.

Na Inglaterra, a deposição atmosférica foi apresentada por NICHOLSON et al., (2003) como sendo a principal fonte de metais pesados (25-85\%) em solos, seguida da incorporação de estercos de animais e de biossólidos (8-40\%). Esses metais estão comumente associados com poluição e toxicidade, mas também incluem alguns elementos que são biologicamente essenciais para os seres vivos em baixas concentrações, tais como Cromo, Cobalto, Cobre, Manganês, Selênio e Zinco, já os elementos Chumbo, Cádmio, Mercúrio, Arsênio, Titânio e Urânio não são essenciais e, por vezes, são denominados metais tóxicos (ALLOWAY, 1995).

Em geral, a seqüência decrescente de acúmulo de metais pesados em plantas, segundo KABATA-PENDIAS \& PENDIAS (2000), é: $\mathrm{Ni}>\mathrm{Zn}>$ $\mathrm{Pb}>\mathrm{Mn}>\mathrm{Cu}$. Os metais tóxicos, mesmo quando

ICoordenação de Engenharia da Produção, Universidade Tecnológica Federal do Paraná (UTFPR), Campus Medianeira. Av. Brasil, 4232, Parque Independência, 85884-000, Medianeira, PR, Brasil. E-mails: carlaschmidt@utfpr.edu.br ou cs910@yahoo.com.br. Autor para correspondência.

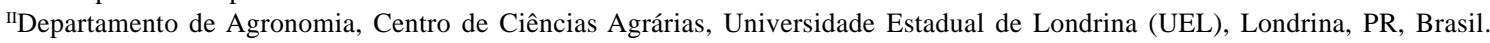

IIICurso de Agronomia, UEL, Londrina, PR, Brasil. 
presentes em pequenas concentrações, podem ocasionar problemas de saúde em plantas e animais. O Brasil é um grande produtor e consumidor de café, por isso fica evidente a importância de se caracterizar a qualidade do produto. Poucos trabalhos foram realizados no sentido de caracterizar a composição de elementos inorgânicos em grãos de café crus produzidos no Estado do Paraná.

O presente estudo teve como objetivos avaliar a concentração de metais pesados em grãos de café da espécie Coffea arabica L., 'IAPAR 59', cultivados em 30 propriedades do Estado do Paraná, sob solos de duas origens, compará-los entre si e com os referenciados em pesquisas científicas e padrões legais. As amostras de café cru foram colhidas em sítios e fazendas produtoras de café de sete cidades paranaenses (Lupinópolis, Centenário do Sul, Miraselva, Prado Ferreira, Astorga, Munhoz de Melo e Londrina), todos relacionados como municípios aptos ao cultivo (MITIDIERI, 2007) e que, com exceção de Londrina, possuem os dois tipos de materiais de origem dos solos (basalto e arenito). Segundo a classificação de Köppen, todas as cidades se encontram no domínio do clima subtropical mesotérmico (Cfa).

Dessas amostras, 15 foram coletadas em solos desenvolvidos a partir de basalto e 15 em solos desenvolvidos a partir de arenito. A média de altitude dos locais foi de 630 metros, para os solos de basalto (valores entre 498 metros e 710 metros acima do nível do mar), e 524 metros, para os solos de arenito (valores entre 390 metros e 647 metros acima do nível do mar). A colheita foi manual no período compreendido entre 15 de março e 12 de abril de 2007. Todas as lavouras amostradas adotavam a tecnologia de plantio adensado. Deu-se preferência para os frutos localizados na parte média da planta e procurou-se colher frutos que estivessem em sua maioria no estágio cereja. A secagem foi ao sol, em terreiro convencional, localizado em uma das propriedades ( $23^{\circ} 30^{\prime}$ S e $51^{\circ} 17^{\prime}$ $\mathrm{W})$, em altitude de $710 \mathrm{~m}$. As amostras em coco foram estocadas em câmara fria e seca da Universidade Estadual de Londrina (UEL), em Londrina, Paraná (PR). A cultivar estudada foi a 'IAPAR 59'.

Trinta gramas de cada uma das amostras de café cru, na forma de grãos, foram beneficiadas com descascador de café manual no dia 18 de junho de 2007, posteriormente, foram homogeneizadas em moinho de facas com refrigeração até a obtenção de partículas perfeitamente pulverizadas e de tamanho uniforme. Utilizou-se o método de digestão por via seca (cinzas), de acordo com o seguinte procedimento: foram pesados $1,0000 \mathrm{~g} \pm 0,0011 \mathrm{~g}$ da amostra de café em cadinhos de porcelana e incinerados em mufla, à temperatura de $450^{\circ} \mathrm{C}$, durante 24 horas. As cinzas foram dissolvidas com 2,1mL de ácido clorídrico concentrado e diluídas em balões volumétricos de $50 \mathrm{~mL}$ com água bidestilada. As determinações dos minerais: $\mathrm{Cr}, \mathrm{Co}, \mathrm{Ni}$, $\mathrm{Pb}, \mathrm{Cd}, \mathrm{Cu}, \mathrm{Zn}$ e $\mathrm{Mn}$ foram realizadas nas amostras e quantificadas pela técnica de espectrometria de emissão atômica com fonte de plasma, em equipamento Thermo Jarrel-ash ICAP 61E (ICP-EAS), modelo spectrometer. Os resultados médios, valores mínimos e máximos encontrados para os oito metais avaliados, nas 30 propriedades estudadas, podem ser observados na tabela 1.

Verificou-se que os valores mais elevados, para vários dos metais analisados, ocorreram nas mesmas propriedades, já, nas outras lavouras, foram encontrados valores mais baixos para a maioria dos elementos analisados. A tabela com todos os resultados obtidos pode ser encontrada em SCHMIDT (2008). Esse resultado pode ser explicado por possíveis contaminações locais via água, excesso de fertilizantes, corretivos, defensivos ou mesmo aos valores de $\mathrm{pH}$ desses solos, pois os metais pesados apresentam maior mobilidade em solos ácidos (KIEKENS \& COTTENIE, 1985). Entretanto, esses fatores não foram avaliados neste estudo. Alguns autores atribuem ao material de origem o componente principal na distribuição dos metais pesados no solo (MITCHELL, 1964; NALOVIC, 1969; FERREIRA et al., 1994). Nas plantas analisadas neste estudo, os valores médios acrescidos e subtraídos de seus respectivos desvios-padrão não foram mais elevados para os solos basálticos, mais argilosos (Tabela 1).

Os adubos comerciais, utilizados com a finalidade de suprir micronutrientes, comprovadamente apresentam em sua composição, além dos elementos desejáveis, metais pesados tóxicos, principalmente Cádmio, Chumbo, Cromo (GONÇALVES JR. \& PESSOA, 2002), Zinco e Níquel (AMARAL SOBRINHO et al., 1992). Até o momento, não há dados que permitam indicar níveis de tolerância desses elementos indesejáveis nos fertilizantes (ALCARDE \& RODELLA, 2003). Outro fator a ser lembrado é a proximidade das plantações de cidades e rodovias, onde a contaminação pode ser bem maior, mas a interferência desses fatores também não foi verificada neste estudo.

A concentração de Cromo em plantas comestíveis que crescem em solos não contaminados fica na faixa do não-detectável até $0,19 \mathrm{mg} \mathrm{kg}^{-1}$ (SCHROEDER et al., 1962). Os valores médios encontrados nos grãos foram maiores que $0,19 \mathrm{mg} \mathrm{kg}^{-1}$ e maiores que os geralmente observados em plantas, sendo que tais valores podem até ocasionar problemas de toxidez nas plantas. O Cobalto não tem limites 
Tabela 1 - Teores médios de metais pesados encontrados nos grãos de café cru, colhidos nas trinta propriedades, em mg kg-1.

\begin{tabular}{|c|c|c|c|}
\hline Elementos & Média \pm Desvio padrão & Teor mínimo & Teor máximo \\
\hline \multicolumn{4}{|c|}{-------------------------------------Resultados das amostras provenientes das 15 propriedades no basalto------------------------------ } \\
\hline Cromo & $0,97 \pm 1,07$ & 0 & 3,28 \\
\hline Cobalto & $0,31 \pm 0,23$ & 0 & 0,76 \\
\hline Níquel & $0,46 \pm 0,57$ & 0 & 2,01 \\
\hline Chumbo & $0,47 \pm 0,85$ & 0 & 2,74 \\
\hline Cádmio & $0,08 \pm 0,11$ & 0 & 0,41 \\
\hline Cobre & $14,37 \pm 1,4$ & 12,22 & 16,9 \\
\hline Zinco & $4,28 \pm 1,04$ & 2,87 & 6,5 \\
\hline Manganês & $29,04 \pm 8,97$ & 14,13 & 47,85 \\
\hline Cromo & $0,76 \pm 0,23$ & 0 & 2,79 \\
\hline Cobalto & $0,25 \pm 0,21$ & 0 & 0,56 \\
\hline Níquel & $0,39 \pm 0,44$ & 0 & 1,62 \\
\hline Chumbo & $0,35 \pm 0,54$ & 0 & 1,61 \\
\hline Cádmio & $0,04 \pm 0,06$ & 0 & 0,17 \\
\hline Cobre & $12,73 \pm 1,68$ & 10,1 & 17,4 \\
\hline Zinco & $4,05 \pm 0,88$ & 2,5 & 5,24 \\
\hline Manganês & $43,63 \pm 26,83$ & 19,85 & 104,65 \\
\hline
\end{tabular}

estabelecidos na ANVISA (BRASIL, 1965 e 1998) ou na ABIA (1985), para se estabelecer uma comparação dos teores obtidos neste trabalho. Podemos citar os valores obtidos por MORGANO et al. (2002), que também avaliaram a quantidade desse elemento em grãos de café crus e encontraram quantidades entre $0 \mathrm{e}$ $1,2 \mathrm{mg} \mathrm{kg}^{-1}$ e PAULUCI et al., (2000), que encontraram teores médios entre 0 e $0,554 \mathrm{mg} \mathrm{kg}^{-1}$ para diferentes Estados brasileiros estudados, e os valores encontrados foram entre 0 e 1,16 $\mathrm{mg} \mathrm{kg}^{-1}$ para o Estado de São Paulo; 0 e 0,183 $\mathrm{mg} \mathrm{kg}^{-1}$ para a Bahia; 0 e 0,554mg $\mathrm{kg}^{-1}$ para Minas Gerais e 0 e 0,038mg kg ${ }^{-1}$ para o Paraná. Percebe-se que os teores aqui apresentados foram mais elevados, o que pode sugerir um aumento desse metal ao longo dos anos.

Os valores de Cobre, em peso de produto seco, encontrados na literatura variam na faixa de 11 a $24 \mathrm{mg} \mathrm{kg}^{-1}$ e 18 a $34 \mathrm{mg} \mathrm{kg}^{-1}$ em café e chá, respectivamente, sendo considerados elevados, quando comparados a outros alimentos (SLOOFF et al., 1989). Em relação ao Manganês, as maiores concentrações desse elemento são encontradas em vegetais, principalmente nos cereais, em verduras de folhas e chás, abacates, cerejas e nozes. As dietas ricas nesses produtos podem chegar a fornecer aproximadamente $18 \mathrm{mg} \mathrm{dia}^{-1}$, e a ingestão média fica entre 2 e $9 \mathrm{mg} \mathrm{dia}^{-1}$ para uma pessoa de $70 \mathrm{~kg}$, porém o máximo aceitável seria de 11mg dia-1 (GREGER, 1999;
ASCHNER, 2000; WHO, 2001; LJUNG \& VAHTER, 2007).

Ao se analisarem os maiores valores obtidos para os oito metais nos grãos crus de cafés, supondo um consumo diário máximo de café de $500 \mathrm{~mL}$ preparados com $50 \mathrm{~g}$ de pó proveniente dos grãos analisados, podese observar que, se todo o metal presente fosse extraído, teríamos um consumo de $0,164 \mathrm{mg} \mathrm{dia}^{-1}$ de Cromo; 0,038 $\mathrm{mg} \mathrm{dia}^{-1}$ de Cobalto; 0,1 $\mathrm{mg}_{\text {dia }}{ }^{-1}$ de Níquel, 0,137mg dia $^{-1}$ de Chumbo, 0,02mg dia-1 de Cádmio, 0,845 $\mathrm{mg} \mathrm{dia}^{-1}$ de Cobre, 0,325mg dia ${ }^{-1}$ de Zinco e 5,2mg dia ${ }^{-1}$ de Manganês, que individualmente não excederiam os valores máximos diários aceitáveis citados em SCHMIDT (2008). Porém, existe a necessidade de se quantificar o consumo desses elementos químicos no restante da dieta, bem como os dados da influência da torra e do preparo do café na manutenção ou eliminação desses teores de metais inicialmente presentes nos grãos.

\section{REFERÊNCIAS}

ABIA. Compêndio da legislação dos alimentos. São Paulo, 1985.

ALCARDE, J.C.; RODELLA, A.A. Qualidade e legislação de fertilizantes e corretivos. In: CURI, N. et al. Tópicos em ciência do solo. Campinas: Sociedade Brasileira de Ciência do Solo, 2003. V.3, p.291-334.

ALLOWAY, B.J. Heavy metals in soils. London: Blackie Academic \& Professional, 1995. 368p.

Ciência Rural, v.39, n.5, ago, 2009. 
AMARAL SOBRINHO, N.M.B. et al. Metais pesados em alguns fertilizantes e corretivos. Revista Brasileira de Ciência do Solo, Campinas, v.16, n.2, p.271-276, 1992.

ASCHNER, M. Manganese: brain transport and emerging research needs. Environmental Health Perspectives, Research Triangle Park, v.108, n.S3, p.429-432, 2000. (Supplements).

BRASIL. Decreto n55.871, de 26 de março de 1965. Modifica o Decreto $\mathrm{n}^{\circ} 50.040$, de 24 de janeiro de 1961, referente a normas reguladoras do emprego de aditivos para alimentos, alterado pelo Decreto n691, de 13 de março de 1962. Diário Oficial [da] República Federativa do Brasil, Brasília, 09 abr. 1965. Seção1.

BRASIL. Portaria nº85, de 27 de agosto de 1998. Diário Oficial [da] República Federativa do Brasil, Brasília, 28 ago. 1998. Seção1.

FERREIRA, S.A.D. et al. Relações entre magnetização, elementos traços e litologia de duas seqüências de solos do estado de Minas Gerais. Revista Brasileira de Ciência do Solo, Campinas, v.18, n.2, p.167-174, 1994.

GONÇALVES JR., A.C.; PESSOA, A.C. dos S. Fitodisponibilidade de Cádmio, Chumbo e crômio, em soja cultivada em argissolo vermelho eutrófico a partir de adubos comerciais. Scientia Agraria, Curitiba, v.3, n.1-2, p.19-23, 2002.

GREGER, J.L. Nutrition versus toxicology of manganese in humans: evaluation of potential biomarkers. Neurotoxicology, Little Rock, v.20, n.2-3, p.205-212, 1999.

KABATA-PENDIAS, A.; PENDIAS, $\mathrm{H}$. Trace elements in soils and plants. 4.ed. Boca Raton: CRC, 2000. 413p.

KIEKENS; L.; COTTENIE, A. Plinciples of investigations on the mobility and plant uptake of heavy metals. In: LESCHBER, R. et al. (Eds.). Chemical methods for assessing bioavailable metals in sludges and soils. New York: Elsevier, 1985. p.21-32.

LJUNG, K.; VAHTER, M. Time to re-evaluate the guideline value for manganese in drinking water? Environmental Health Perspectives, Research Triangle Park, v.115, n.11, p.1533-1538, 2007.

MITCHELL, R.L. Trace elements in soils. In: BEAR, F.E. (Ed.). Chemistry of the soil. New York: Reinhold, 1964. p.320-368.
MITIDIERI, F.J. Nota técnica. Diário Oficial [da] República Federativa do Brasil, Brasília, 10 ago. 2007, n.154, Sessão 1.

MORGANO, M.A. et al. Determinação de minerais em café cru. Ciência e Tecnologia de Alimentos, Campinas, v.22, n.1, p.19-23, 2002. Disponível em:<http:// www.scielo.br/scielo.php?script=sci_arttext \&pid=S010120612002000100004\&lng=en \&nrm=iso >. Doi: 10.1590/ S0101-20612002000100004

NALOVIC, L. Etude spectrographique des éléments traces et leur distribution dans quelques types de sols de Madagascar. Cahiers Orstom. Serie Pedologie, Bondy, v.7, n. 2, p.133181, 1969

NICHOLSON, F.A. et al. An inventory of heavy metals inputs to agricultural soils in England and Wales. Science of the Total Environment, Amsterdam, v.311, n.1-3, p.205-219, 2003. Disponível em: <http://www.sciencedirect.com/ science?_ob=ArticleURL\&_udi=B6V78-48GF32P_$2 \&$ _user $=687358 \&$ \&rdoc $=1 \&$ _fmt $=\&$ _orig $=$ search $\&$ _ sort $=$ d \& view $=$ c $\&$ _ a c c t $=$ C $000037899 \&_{-}$vers i o $n=1 \&$ u r l Vers i o $n=0 \&$ u s e r i d $=687358 \& \mathrm{md} 5=21474 \mathrm{~d} 54 \mathrm{bdc} 8 \mathrm{~b} 9 \mathrm{~b} 554 \mathrm{cfde} 1550 \mathrm{~d} 478 \mathrm{c} 7 \mathrm{P}$. Doi:10.1016/S0048-9697(03)00139-6.

PAULUCI, L.F et al. Minerais em café cru do Brasil. In: SIMPÓSIO DE PESQUISA DOS CAFÉS DO BRASIL, 1., 2000, Poços de Caldas. Anais... Brasília: EMBRAPA Café; Belo Horizonte: MINASPLAN, 2000. 2v., p.726-729. 1490p.

SCHMIDT, C.A.P. Caracterização qualitativa, química e microbiológica de cafés de solos de basalto e arenito. 2008. 160f. Tese (Doutorado em Agronomia - área de concentração Fitotecnia) - Curso do Pós-graduação em Agronomia, Universidade Estadual de Londrina, Londrina. Disponível em: <http://bibliotecadigital.uel.br/document/ ?code=vtls000128883>. Acesso em: 20 out. 2008.

SCHROEDER, H.A. et al. Abnormal trace metals in man: chromium. Journal of Chronic Disease, Washington, v.15, n.1, p. 941-964, 1962.

SLOOFF W. et al. Integrated criteria document copper. Bilthoven, The Netherlands: Institute of Public Health and Environmental Protection, 1989. 147p. (Report n.758474009). Disponível em: <http://www.rivm.nl/ bibliotheek/rapporten/ 758474009.pdf>. Acesso em: 01 ago. 2007.

WHO. Manganese: air quality guidelines. 2.ed. Copenhagen: Regional Office for Europe, 2001. 13p. 